\section{Mulheres vítimas de violência sexual: meios coercitivos e produção de lesões não-genitais}

\author{
Female victims of sexual abuse: \\ coercive methods and non-genital injuries
}

\begin{abstract}
This study aims to analyze the coercive methods used by sex offenders and the occurrence of nongenital injuries in female children, adolescent, and adult victims of sexual abuse reported to the Women's Police Precinct and examined at the Department of Forensic Medicine in Ribeirão Preto, São Paulo State, Brazil, from 1996 to 2000. Age distribution followed the criteria established by Brazil's Statute for Children and Adolescents (the prevailing legislation on issues pertaining to minors). Physical violence was the most frequently used form of coercion against adults (44.1\%) and adolescents (25.0\%), followed by serious threat in $36.5 \%$ and $17.0 \%$ of the cases, respectively. Presumed violence by innocentia consilii occurred in $94.1 \%$ of the children and $42.8 \%$ of the adolescents. Minor nongenital injuries were found in $7.8 \%$ of the cases, involving children (3.0\%), adolescents (7.2\%), and adults (14.4\%), with no weapons involved in $75.0 \%$ of these cases. A decrease in the number of cases with injuries was observed in relation to knives (14.3\%) and handguns (10.7\%) used against adult and adolescent victims.
\end{abstract}

Wounds and Injuries; Violence; Gender
Jair Naves dos Reis 1

Carmen Cinira Santos Martin 1 Maria das Graças Carvalho Ferriani 2

\section{Introdução}

A violência sexual, uma das facetas do complexo fenômeno violência, desconhece barreiras de classe social, tipos de cultura, níveis sócioeconômicos e limitações individuais. Seus incidentes ocorrem tanto no espaço privado quanto no público, atingindo pessoas de ambos os sexos e de todas as faixas etárias.

Nos Estados Unidos, dados estatísticos obtidos por meio do National Crime Victimization Survey demonstram que cerca de $300 \mathrm{mil}$ a 350 mil ofensas sexuais são perpetradas anualmente contra vítimas com idade superior a 12 anos e cerca de 300 mil, contra aquelas com idade inferior a este limite 1,2. No Brasil, carecemos de dados globais sobre a violência sexual, fato que proporcionaria um melhor dimensionamento e entendimento do fenômeno em nosso meio ${ }^{3}$.

Utilizando as relações de gênero, de poder e meios coercitivos representados por formas de constrangimento tais como ameaças, intimidações, armas ou mesmo força física, diante dos quais a resistência das vítimas pode acarretar riscos gravíssimos, inclusive da própria vida, os ofensores impõem-lhes a entrega de si para a realização de seu intento, transformando-as em objetos sexuais. Após a agressão, as vítimas apresentam necessidade de atenção médica e psicológica para o cuidado e tratamento das conseqüências do delito, e viven- 
ciam situações de ordem legal ao serem acionadas as normas jurídicas do direito. Entre essas situações, coexiste a realização de exame médico-legal que visa a assegurar a cadeia de evidências do crime para propósitos forenses.

Mesmo não sendo um problema específico da saúde e sim da sociedade, diante do grande número de vítimas, dos agravos e ameaças à vida, às relações interpessoais e à saúde, a violência adquiriu proporção de um complexo problema de saúde pública 4,5 . Na violência sexual, além dos danos psicológicos, do risco de contrair doenças sexualmente transmissíveis e o vírus da imunodeficiência adquirida (HIV), verifica-se a possibilidade da ocorrência de gravidez pós-estupro e de lesões genitais e não-genitais decorrentes da violência presente nesse tipo de ofensa 6 .

Passada a situação de emergência no atendimento aos agravos da violência sexual, a vítima se vê diante das ações desenvolvidas pelos órgãos judiciários responsáveis pela responsabilização legal do ofensor. Nessas instituições, o incidente denunciado é tipificado e passa a ser um crime, estabelecendo-se uma relação entre ofensor/ofendido e gerando-se o dolo e a culpa do agente do delito. Ocorre então, a responsabilização legal do ofensor que recebe a punição pelos danos causados à vítima, segundo o que lhe corresponde pelo crime que cometeu.

Nos crimes de estupro e atentado violento ao pudor, em que a faculdade de livre escolha do parceiro sexual é violada pelo uso de violência ou grave ameaça, o Código Penal Brasileiro vigente 7 determina que além do constrangimento, da conjunção carnal ou do ato libidinoso diverso desta, a violência ou a grave ameaça sejam elementos integrantes do delito. Nesses crimes, os sinais do uso da força expressos por meio de lesões corporais produzidas pela agressão ou resistência são evidências valiosas na verificação do uso de violência. No Brasil, diante da inexistência de tais lesões, o julgamento legal da ocorrência de violência encontra-se fundamentado nos casos de sua presunção.

A resolubilidade dos casos de ofensas sexuais e o combate a este tipo de violência requerem que junto às ações de atendimento emergencial médico e psicológico prestado às vítimas, ocorram as ações judiciárias, nas quais a denúncia, a instauração do processo e o julgamento do ofensor são fatores importantes para que a agressão não se repita.

Para Deslandes 8, a violência pertence à nova perspectiva que busca se consolidar no campo da saúde coletiva, que reconhece o conhecimento como produção de complexidade, articulando as tecnociências com as ciências hu- manas, integrando as dimensões coletivas e individuais, objetivas e simbólicas, quantitativas e qualitativas. Este grande desafio, demanda a articulação interna da saúde e desta com outros setores. Apesar de pesquisas multidisciplinares estarem surgindo na literatura pertinente, observa-se a carência de estudos sobre informações dirigidas ao impacto de fatores específicos envolvidos nas perpetrações dos crimes sexuais.

Diante do exposto, o presente estudo tem como objetivo analisar os meios coercitivos utilizados pelos ofensores e a produção de lesões não-genitais em mulheres crianças, adolescentes e adultas, vítimas de violência sexual, categorizadas segundo o critério legal de idade estabelecido pelo Estatuto da Criança e do Adolescente 9 .

\section{Método}

O estudo empreendeu a análise de casos de crimes de estupro e atentado violento ao pudor não fatais, cometidos contra mulheres de quaisquer idades, notificados pela Delegacia de Defesa da Mulher, cujas vítimas foram submetidas a exames periciais no Núcleo de Perícias Médico-Legais de Ribeirão Preto, São Paulo, no período de 1996 a 2000.

O estupro é definido no artigo 213 do Código Penal Brasileiro 7 como "constranger mulher à conjunção carnal, mediante violência ou grave ameaça" e o atentado violento ao pudor, pelo artigo 214, como "constranger alguém, mediante violência ou grave ameaça, a praticar ou permitir que com ele se pratique ato libidinoso diverso da conjunção carnal”. Constranger significa obrigar, coagir alguém a fazer algo contra a vontade. No primeiro delito, o elemento conjunção carnal (cópula pênis-vagina) indica que as vítimas são necessariamente, mulheres. No segundo, com atos diversos deste tipo de coito, como o sexo oral, anal, manipulação de genitais e sucções volúpticas, o crime pode ser praticado contra ambos os sexos. A grave ameaça consiste na promessa de realizar mal à vítima ou aos seus familiares. Ainda no Código Penal Brasileiro, o artigo 224, apesar da inexistência de efetiva violência física, presume o crime em situações onde a vítima se apresenta incapaz de defender-se ou evitar a ofensa. São elas: a idade menor que 14 anos, onde a vítima não possui condições de compreender e avaliar as conseqüências do ato sexual (innocentia consilii); a alienação e debilidade mental e a incapacidade para resistir, devendo o agente do crime conhecer essas condições. 
Os dados foram obtidos com base em informações contidas nos boletins de ocorrências policiais e laudos de exames de corpo de delito de conjunção carnal e atos libidinosos elaborados pelas autoridades legais. Elegeu-se para análise as variáveis: os meios coercitivos empregados pelo ofensor, representados pela violência física, violência presumida e grave ameaça; o uso ou não de armas convencionais como as de fogo ou brancas; a utilização de objetos à semelhança de armas e a presença de lesões não-genitais constatadas e descritas nos laudos periciais. As lesões não-genitais são entendidas como lesões produzidas pelo uso da violência física, de objetos ou de armas sobre a superfície corporal, que não estejam restritas à área genital. Na maioria dos casos de violência sexual, as lesões genitais como roturas himenais, lacerações e fissuras vaginais são causadas pela ação traumática do pênis.

Na distribuição dos casos segundo a faixa etária, utilizou-se a idade em anos completos registrada no dia dos fatos e o critério estabelecido pelo Estatuto da Criança e do Adolescente 9 , que considera criança a pessoa até 12 anos de idade incompletos, e adolescente aquela entre 12 e 18 anos de idade. Foram consideradas adultas, vítimas com idade superior a 18 anos. Para melhor observação das diferenças existentes na abordagem por idade, utilizou-se o critério cronológico segundo o contexto legal descrito e o da Organização Mundial da Saúde (OMS), no qual crianças são pessoas com idade inferior a dez anos completos, adolescentes aquelas com idade maior ou igual a dez anos completos e menor que vinte anos completos, e adultas as com idade superior a vinte anos.

O presente estudo, que é parte de uma ampla pesquisa sobre violência sexual contra mulheres, teve seu protocolo de pesquisa submetido à revisão ética e aprovado pelo Comitê de Ética em Pesquisa do Hospital das Clínicas da Faculdade de Medicina de Ribeirão Preto da Universidade de São Paulo.

\section{Resultados}

No período proposto e atingindo ambos os sexos, ocorreram 391 casos de crimes contra a liberdade sexual com uso de violência e grave ameaça, notificados e submetidos à perícia médico-legal. Destes, 33 (8,4\%) foram excluídos por se tratarem de indivíduos do sexo masculino. Dos 358 crimes cometidos contra mulheres, $(91,6 \%)$ que se adequaram aos critérios previamente estabelecidos, 197 eram de estupro, 129 de atentados violentos ao pudor e 32, de vítimas que sofreram os dois tipos de crime. Segundo o critério de idade estabelecido pelo Estatuto da Criança e do Adolescente, foram vitimizadas 135 crianças (37,7\%), 112 adolescentes $(31,3 \%)$ e 111 adultas (31,0\%) e pelo da OMS, $100(27,9 \%), 162(45,3 \%)$ e $96(26,8 \%)$, respectivamente.

A violência física foi o meio coercitivo mais empregado contra mulheres adultas e adolescentes, seguida da grave ameaça nessas mesmas vítimas. Tais formas de coerção não foram utilizadas contra crianças, observando-se nesse grupo etário, o predomínio da violência presumida como condição já definida por lei. A presunção da violência também foi verificada nos casos de adolescentes com idade menor que 14 anos. As condições de violência presumida por alienação ou debilidade mental foram constatadas acometendo maior número de vítimas adultas, numa proporção três vezes maior que a evidenciada em adolescentes na mesma situação. A presunção da violência pela incapacidade para resistir foi observada nas vitimizações de adolescentes e adultas, sendo as últimas, as mais acometidas por esse tipo de constrangimento (Tabela 1).

Lesões não-genitais foram evidenciadas num pequeno número de incidentes, sendo todas de natureza leve. Na medida que a faixa etária das vítimas aumenta, constatou-se um maior número desse tipo de lesões (Tabela 2).

A maioria dos crimes não envolveu o uso de armas ou objetos na agressão. Quando fizeram parte dos incidentes, o revólver foi a arma mais utilizada nos delitos cometidos contra vítimas adultas, fato também observado nas adolescentes. A faca foi a mais utilizada das armas brancas e a segunda empregada em maior número contra vítimas adultas e adolescentes. A associação entre revólver e faca foi encontrada em apenas um caso notificado. Nos crimes cometidos contra crianças, não se observou o emprego de objetos ou armas convencionais. Quanto ao uso de objetos como armas, verificou-se maior ocorrência de sua utilização nos incidentes com adolescentes, seguindo-se daqueles envolvendo as adultas (Tabela 3).

As lesões não-genitais predominaram nos crimes que não envolveram o uso de armas. Contudo, nos casos em que facas foram empregadas pelos ofensores, vítimas adultas e adolescentes sofreram tais lesões, sendo as primeiras as mais acometidas. Ao serem utilizados revólveres, esses tipos de lesões foram evidenciados apenas nas adultas. Nos casos em que existiu o emprego de objetos, observou-se a ausência de lesões não-genitais (Tabela 4). 
Tabela 1

Distribuição dos casos de estupro e atentado violento ao pudor, segundo os meios coercitivos

empregados nas faixas etárias analisadas, ocorridos no período de 1996 a 2000.

\begin{tabular}{|c|c|c|c|c|c|c|c|c|}
\hline \multirow[t]{2}{*}{ Meio coercitivo } & \multicolumn{2}{|c|}{ Crianças } & \multicolumn{2}{|c|}{ Adolescentes } & \multicolumn{2}{|c|}{ Adultas } & \multicolumn{2}{|c|}{ Total } \\
\hline & $\mathrm{n}$ & $\%$ & $\mathrm{n}$ & $\%$ & $\mathrm{n}$ & $\%$ & $\mathrm{n}$ & $\%$ \\
\hline Violência física & $0(0)^{1}$ & $0(0)$ & $28(33)$ & $25,0(20,4)$ & $49(44)$ & $44,1(45,9)$ & 77 & 21,5 \\
\hline \multicolumn{9}{|l|}{ Violência presumida } \\
\hline Idade menor que 14 anos & 127 (99) & $94,1(99,0)$ & $48(76)$ & $42,8(46,9)$ & 2 & 2 & 175 & 48,9 \\
\hline Alienação/debilidade mental & $1(0)$ & $0,7(0,0)$ & $2(4)$ & $1,8(2,5)$ & $6(5)$ & $5,4(5,2)$ & 9 & 2,5 \\
\hline Incapacidade para resistir & $0(0)$ & $0,0(0,0)$ & $1(2)$ & $0,9(1,2)$ & $2(1)$ & $1,8(1,0)$ & 3 & 0,9 \\
\hline Grave ameaça & $0(0)$ & $0,0(0,0)$ & $19(24)$ & $17,0(14,8)$ & $40(35)$ & $36,1(36,5)$ & 59 & 16,5 \\
\hline Outros & $5(1)$ & $3,7(1,0)$ & $11(18)$ & $9,9(11,1)$ & $10(7)$ & $9,0(7,3)$ & 26 & 7,2 \\
\hline Sem informações & $2(0)$ & $1,5(0,0)$ & $3(5)$ & $2,6(3,1)$ & $4(4)$ & $3,6(4,1)$ & 9 & 2,5 \\
\hline Total & $135(100)$ & $100,0(100,0)$ & $112(162)$ & $100,0(100,0)$ & $111(96)$ & $100,0(100,0)$ & 358 & 100,0 \\
\hline
\end{tabular}

Fonte: Boletins de Ocorrências Policiais da Delegacia de Defesa da Mulher, Ribeirão Preto.

1 Entre parênteses, distribuição dos casos segundo o critério de idade da OMS.

2 Não se aplica.

Tabela 2

Distribuição dos casos de estupro e atentado violento ao pudor, segundo a existência e natureza

de lesões extragenitais nas faixas etárias analisadas, ocorridos no período de 1996 a 2000.

\begin{tabular}{|c|c|c|c|c|c|c|c|c|}
\hline \multirow[t]{2}{*}{ Lesões extragenitais } & \multicolumn{2}{|c|}{ Crianças } & \multicolumn{2}{|c|}{ Adolescentes } & \multicolumn{2}{|c|}{ Adultas } & \multicolumn{2}{|c|}{ Total } \\
\hline & $\mathrm{n}(\mathrm{OMS})^{\star}$ & $\%$ & $\mathrm{n}(\mathrm{OMS})^{\star}$ & $\%$ & $\mathrm{n}(\mathrm{OMS})^{*}$ & $\%$ & $n$ & $\%$ \\
\hline Ausentes & $131(96)$ & $97,0(96,0)$ & $104(153)$ & $92,8(94,4)$ & $95(81)$ & $85,6(84,4)$ & 330 & 92,2 \\
\hline \multicolumn{9}{|l|}{ Presentes } \\
\hline Leves & $4(4)$ & $3,0(4,0)$ & $8(9)$ & $7,2(6,6)$ & $16(15)$ & $14,4(15,6)$ & 28 & 7,8 \\
\hline Graves & $0(0)$ & $0,0(0,0)$ & $0(0)$ & $0,0(0,0)$ & $0(0)$ & $0,0(0,0)$ & 0 & 0,0 \\
\hline Total & $135(100)$ & $100,0(100,0)$ & $112(162)$ & $100,0(100,0)$ & $111(96)$ & $100,0(100,0)$ & 358 & 100,0 \\
\hline
\end{tabular}

Fonte: Arquivos do Núcleo de Perícias Médico-Legais - RP.

* Distribuição dos casos segundo o critério de idade da OMS.

\section{Discussão}

Na literatura nacional sobre violência sexual, nota-se a carência de trabalhos com análises de fatores contextuais, tais como os abordados por este estudo, e a idade das vítimas distribuídas segundo o critério legal estabelecido pelo Estatuto da Criança e do Adolescente. Por estar esse critério restrito ao circuito de responsabilização do Brasil, a maioria das pesquisas existentes se relacionam com o circuito de atendimento nos serviços de atenção à saúde, utilizando a distribuição por idade segundo a OMS. Tal distribuição proporciona a comparação de dados epidemiológicos com trabalhos realizados em nível nacional ou internacional.

Juridicamente, a idade constitui fator importante já que o legislador presume a violên- cia em menores de quatorze anos e considera sujeitos de direitos as crianças e adolescentes categorizados segundo a faixa de idade prevista no Estatuto da Criança e do Adolescente. Nesse contexto, uma pessoa de 11 anos é considerada criança pelo critério do Estatuto da Criança e do Adolescente, e pela OMS seria adolescente. Uma vítima adolescente de 19 anos, segundo os parâmetros da OMS, seria adulta pelo Estatuto da Criança e do Adolescente, não gozando da proteção integral dessa lei.

Freqüentemente, as instituições de saúde são os locais para onde as vítimas de violência sexual espontaneamente se dirigem, ao contrário do que se observa nas instituições legais. Na Noruega, Bang 10 constatou que um serviço de emergência realizou quatro vezes mais atendimentos a vítimas de ofensas sexuais que o 
Distribuição dos casos de estupro e atentado violento ao pudor, segundo o tipo de arma utilizada pelo ofensor nas faixas etárias analisadas, ocorridos no período de 1996 a 2000.

\begin{tabular}{|c|c|c|c|c|c|c|c|c|}
\hline \multirow[t]{2}{*}{ Tipos de armas } & \multicolumn{2}{|c|}{ Crianças } & \multicolumn{2}{|c|}{ Adolescentes } & \multicolumn{2}{|c|}{ Adultas } & \multicolumn{2}{|c|}{ Total } \\
\hline & $\mathrm{n}(\mathrm{OMS})^{*}$ & $\%$ & $\mathrm{n}(\mathrm{OMS})^{*}$ & $\%$ & $\mathrm{n}(\mathrm{OMS})^{\star}$ & $\%$ & $n$ & $\%$ \\
\hline Revólver & $0(0)$ & $0,0(0,0)$ & $9(14)$ & $47,4(56,0)$ & $21(16)$ & $52,5(47,0)$ & 30 & 50,8 \\
\hline Faca & $0(0)$ & $0,0(0,0)$ & $5(5)$ & $26,3(20,0)$ & $13(13)$ & $32,5(38,0)$ & 18 & 30,5 \\
\hline Canivete & $0(0)$ & $0,0(0,0)$ & $0(1)$ & $0,0(4,0)$ & $2(1)$ & $5,0(3,0)$ & 2 & 3,4 \\
\hline Facão & $0(0)$ & $0,0(0,0)$ & $1(1)$ & $5,3(4,0)$ & $0(0)$ & $0,0(0,0)$ & 1 & 1,7 \\
\hline Revólver/Faca & $0(0)$ & $0,0(0,0)$ & $0(0)$ & $0,0(0,0)$ & $1(1)$ & $2,5(3,0)$ & 1 & 1,7 \\
\hline \multicolumn{9}{|l|}{ Objetos } \\
\hline Lima & $0(0)$ & $0,0(0,0)$ & $0(0)$ & $0,0(0,0)$ & $1(1)$ & $2,5(3,0)$ & 1 & 1,7 \\
\hline Chave de fenda & $0(0)$ & $0,0(0,0)$ & $2(2)$ & $10,5(8,0)$ & $1(1)$ & $2,5(3,0)$ & 3 & 5,1 \\
\hline Tesoura & $0(0)$ & $0,0(0,0)$ & $0(0)$ & $0,0(0,0)$ & $1(1)$ & $2,5(3,0)$ & 1 & 1,7 \\
\hline Pau & $0(0)$ & $0,0(0,0)$ & $2(2)$ & $10,5(8,0)$ & $0(0)$ & $0,0(0,0)$ & 2 & 3,4 \\
\hline Total & $0(0)$ & $0,0(0,0)$ & $19(25)$ & $100,0(100,0)$ & $40(34)$ & $100,0(100,0)$ & 59 & 100,0 \\
\hline
\end{tabular}

Fonte: Boletins de Ocorrências Policiais da Delegacia de Defesa da Mulher - RP.

* Distribuição dos casos segundo o critério de idade da OMS.

Distribuição dos casos de estupro e atentado violento ao pudor com lesões extragenitais confirmadas por perícia médico-legal, segundo o emprego ou não de armas nas faixas etárias analisadas, ocorridos no período de 1996 a 2000.

\begin{tabular}{|c|c|c|c|c|c|c|c|c|}
\hline \multirow[t]{2}{*}{ Armas } & \multicolumn{2}{|c|}{ Crianças } & \multicolumn{2}{|c|}{ Adolescentes } & \multicolumn{2}{|c|}{ Adultas } & \multicolumn{2}{|c|}{ Total } \\
\hline & $\mathrm{n}(\mathrm{OMS})^{\star}$ & $\%$ & $\mathrm{n}(\mathrm{OMS})^{*}$ & $\%$ & $\mathrm{n}(\mathrm{OMS})^{\star}$ & $\%$ & $\mathrm{n}$ & $\%$ \\
\hline Revólveres & $0(0)$ & $0,0(0,0)$ & $0(1)$ & $0,0(11,1)$ & $3(2)$ & $18,7(13,3)$ & 3 & 10,7 \\
\hline Facas & $0(0)$ & $0,0(0,0)$ & $1(1)$ & $12,5(11,1)$ & $3(3)$ & $18,7(20,0)$ & 4 & 14,3 \\
\hline Objetos & $0(0)$ & $0,0(0,0)$ & $0(0)$ & $0,0(0,0)$ & $0(0)$ & $0,0(0,0)$ & 0 & 0,0 \\
\hline Sem armas & $4(4)$ & $100,0(100,0)$ & $7(7)$ & $87,5(77,8)$ & $10(10)$ & $62,6(66,7)$ & 21 & 75,0 \\
\hline Total & $4(4)$ & $100,0(100,0)$ & $8(9)$ & $100,0(100,0)$ & $16(15)$ & $100,0(100,0)$ & 28 & 100,0 \\
\hline
\end{tabular}

Fonte: Boletins de Ocorrências Policiais da Delegacia de Defesa da Mulher e arquivos do Núcleo de Perícias Médico-Legais-RP.

* Distribuição dos casos segundo o critério de idade da OMS.

número registrado pelas autoridades legais. Os serviços de saúde são portas de entrada para as quais a maioria das vítimas se dirige, possivelmente, preocupadas com sua integridade e saúde. Fato inverso ocorre com relação à porta de entrada do sistema judiciário, no qual a responsabilização penal do ofensor está vinculada com a notificação do delito. É fato já relatado pela literatura, que grande número de vítimas evita o contato com instituições policiais devido a vários fatores. Dentre eles, cita-se o descrédito, o medo, a morosidade e a noção da inefetividade do sistema, que faz com que os crimes sexuais permaneçam imiscuídos na cifra negra da criminalidade e o número de notificações se mostre menor que os atendimentos assistenciais dispensados às vítimas. Muitas vezes a própria vítima ou seu representante legal, por motivos intrínsecos à relação familiar, não notifica o fato, preferindo primeiramente buscar auxílio médico ou psicológico com medo das conseqüências do abuso sofrido. Evidentemente, no caso de vítimas crianças e adolescentes, após o atendimento realizado pelo setor da saúde, as instituições que as atendem estão obrigadas à notificação, ainda que à revelia da vítima ou representante legal.

Apesar do setor público de saúde ser uma das portas de entrada da maioria das vítimas de violência e proporcionar grande visibilidade do fenômeno, a resolubilidade dos casos requer que se integre esforços de outra porta de 
entrada, a das instituições legais, pelas quais transitam as ações judiciárias de responsabilização e punição dirigidas aos ofensores, então agentes do crime. Se numa realidade verificase a preocupação com os danos causados à vítima, na outra, tais lesões se converterão num nexo entre o ato delituoso e o ofensor. Nos crimes de estupro e atentado violento ao pudor, as lesões corporais de natureza leve são absorvidas nesses crimes, ao passo que as graves são formas qualificadas que constituem hipóteses de crimes hediondos, concorrendo para um aumento da pena imposta ao ofensor.

Estudos revelam que os ofensores sexuais muitas vezes vivenciaram situações de abuso ocorridas na infância, podendo a ofensa estar relacionada a uma recapitulação de sua própria vitimização 11,12. No setor da saúde, a prevenção é uma categoria fundamental significando uma ação antecipada sobre situações de risco. Ao agir sobre os ofensores, responsabilizando-os pelos delitos, as instituições judiciárias desempenham também um papel preventivo, atuando nos fatores de risco e na rede causal das ofensas sexuais, impedindo novas vitimizações e suas conseqüências, bem como, a possibilidade do surgimento de futuros ofensores. Porém, mesmo que tais condições geradoras desse tipo de violência sejam interrompidas, as ações policiais, o mecanismo judiciário e o apoio médico e psicológico às vitimas se revelam como mecanismos secundários de intervenção, pois o delito já aconteceu.

Nossos dados demonstram o predomínio de mulheres (91,6\%) nos casos notificados de vitimização sexual, destacando-se entre elas, as crianças e adolescentes $(69,0 \%)$, fato igualmente observado na literatura mundial. Na distribuição por idade segundo o Estatu to da Criança e do Adolescente, no contingente de 358 vitimizadas, $37,7 \%$ eram crianças, $31,3 \%$ adolescentes e $31,0 \%$ adultas. Pelo critério da OMS e nas mesmas faixas etárias, 27,9\%, 45,3\% e $26,8 \%$.

A violência física foi o meio coercitivo mais utilizado contra mulheres adultas $(44,1 \%)$ e adolescentes $(25,0 \%)$, seguindo-se a grave ameaça em $36,1 \%$ e $17,0 \%$ dos casos nessas vítimas. Ambos os meios não foram empregados contra crianças. Utilizando o critério proposto pela OMS, constata-se que a violência física acometeu $45,9 \%$ das adultas e $20,4 \%$ das adolescentes, e a grave ameaça, $36,5 \%$ e $14,8 \%$ dessas mesmas faixas etárias. Em contraste com esses resultados e utilizando os parâmetros da OMS, Ferreira 13 relata que no Serviço de Atenção Integral à Mulher Vitimada em São Paulo, ocorreu a predominância da grave ameaça como forma de coerção usada contra vítimas adultas $(67,8 \%)$, adolescentes $(63,2 \%)$ e crianças $(22,5 \%)$. Ainda o autor, refere o emprego da violência física em $14,3 \%$ dos casos envolvendo mulheres adultas, em $12,3 \%$ com adolescentes e em $7,0 \%$, crianças.

O processo de dominação e exploração, parte integrante da sociedade, faz com que existam situações de mando e relações violentas entre homens e mulheres. Nesse âmbito, o ofensor por ter mais força física que a mulher e também por ter sua agressividade estimulada pela sociedade em que vive, utiliza o que aprendeu para intimidar e neutralizar a resistência da mulher por meio da violência física ou psicológica. Por outro lado, refletindo a questão de gênero onde o homem detém o poder em suas relações sociais, as mulheres como uma categoria dominada, condicionadas a se submeter a atos de mando, agressões e violências, encontram nos meios coercitivos de força física ou na ameaça de seu uso pelos ofensores, motivo suficiente para cederem às exigências dos mesmos.

No presente estudo, predominou a violência presumida pela menoridade (innocentia consilii), ocorrendo em $94,1 \%$ dos casos com crianças e 42,8\% daqueles com adolescentes, segundo o Estatuto da Criança e do Adolescente. Pela OMS, em $99,0 \%$ e $46,9 \%$, respectivamente. Dados similares foram constatados por Ferreira 13, com a ocorrência dessa forma de violência em 100,0\% dos crimes praticados contra crianças e em $59,5 \%$ contra adolescentes. Esse tipo de violência não precisa ser obrigatoriamente provado, visto que a menoridade, a alienação e a debilidade mental excluem a possibilidade do livre consentimento pela incapacidade de consentir. Não possuindo condições de compreender e avaliar as conseqüências do ato sexual, as crianças e adolescentes menores de 14 anos são vitimizadas por meio do uso da autoridade de um adulto ou pessoa mais velha, muitas vezes aliada à ingenuidade infantil. Nesses casos, inexistindo a violência física e diante da subjetividade da percepção de sentir-se vitimizada, ocorre o julgamento legal que se baseia na diferença de idade existente entre o ofensor e sua vítima.

A condição de violência presumida por alienação e debilidade mental foi constatada em $5,4 \%$ das vítimas adultas, $1,8 \%$ das adolescentes e $0,7 \%$ das crianças, segundo o Estatuto da Criança e do Adolescente, e pelo critério da OMS, em 2,5\% dos casos envolvendo adolescentes e $5,2 \%$ das adultas, inexistindo contra crianças. Para Ferreira 13, a deficiência mental ocorreu numa freqüência duas vezes maior no 
grupo de mulheres adultas (70,0\%) quando comparada ao das adolescentes $(35,1 \%)$, espelhando o observado na distribuição segundo a OMS. Pelo Estatuto da Criança e do Adolescen$t e$, as mulheres adultas apresentaram uma proporção três vezes maior desta condição que as adolescentes e seis vezes maior que a verificada em crianças.

Nos Estados Unidos, Pease \& Frantz 14, realizando revisão de taxas de ofensas sexuais, verificaram que de $68,0 \%$ a $83,0 \%$ desta população serão vitimizadas sexualmente ao longo de suas vidas, o que representa uma taxa 50,0\% mais alta do que aquela observada no restante da população. Por sua condição de vulnerabilidade, tais mulheres apresentarão um maior risco para ofensas sexuais crônicas.

A violência presumida por incapacidade para resistir devido à paralisia foi verificada em $1,8 \%$ dos incidentes contra mulheres adultas de nosso estudo e em $0,9 \%$ das adolescentes.

Em ambos os critérios etários, lesões nãogenitais não foram evidenciadas em $92,2 \%$ dos casos e quando constatadas $(7,8 \%)$, as mesmas foram de natureza leve. Tais resultados assemelham-se àqueles encontrados por Ferreira 13, nos quais, a ausência dessas lesões é verificada em $88,0 \%$ dos casos e nos $12,0 \%$ que as apresentaram, as mesmas foram de natureza leve. Em contraste, Cohen \& Matsuda 15 relatam a ocorrência de lesões não-genitais em $38,8 \%$ dos casos de violência sexual atendidos no Instituto Médico-Legal de São Paulo.

Segundo o Estatuto da Criança e do Adolescente, crianças sofreram lesões leves em 3,0\% dos casos, as adolescentes em $7,2 \%$ e as adultas, em $14,4 \%$, e pela OMS, $4,0 \%, 5,6 \%$ e $15,6 \%$, respectivamente. A constatação de lesões nãogenitais nas crianças desse estudo pode estar relacionada a outras situações que não o emprego de força efetiva, já que as informações indicam a ausência da violência física como meio coercitivo empregado contra essa faixa de idade.

Algumas vítimas de ofensas sexuais apresentam mais lesões não-genitais que outras. Fatores como a idade, o vínculo com o ofensor e o uso de armas, entre outros, influenciam na sua produção. No grupo de crianças, essas lesões são sinais expressivos do uso de violência física já que as mesmas apresentam dificuldade para reagir contra ofensores com porte físico e idades maiores que as suas. Quando ausentes, os ofensores podem ter evitado a produção de injúrias físicas para não agravar o delito ou então, utilizado a sedução e a ameaça na interação cotidiana com suas vítimas, como se observa nos casos de violência sexual crôni- ca e intrafamiliar. Nas adolescentes e adultas, as lesões podem provir de situações onde a resistência física se fez presente como tentativa para impedir a realização da ofensa, e estarem ausentes em incidentes em que se empregou um uso mínimo de violência. Ou ainda, a vítima não ofereceu resistência sob grave ameaça ou uso de armas, por medo de injúrias sérias ou morte. Esta observação converge para os casos de grave ameaça analisados, nos quais constatou-se que todos envolveram o uso de armas ou objetos.

A maioria dos crimes foi cometida sem a utilização de armas (83,5\%), fato similarmente observado por Pimentel et al. 16, que relatam a ausência das mesmas em $60,0 \%$ das agressões sexuais, e por Rennison 2 em 90,0\% das vitimizações ocorridas nos Estados Unidos. Ainda nesse país, com dados do National Crime Victimization Survey, a autora relata o uso de armas em $5,0 \%$ dos crimes, com a presença de armas de fogo e facas em $1,0 \%$ deles.

Armas foram utilizadas em $16,5 \%$ dos casos, com revólveres respondendo por $50,8 \%$ das armas empregadas nos crimes e as facas, por $30,5 \%$. Na análise por faixa etária, os crimes cometidos contra crianças não envolveram o uso de armas ou objetos. O revólver destaca-se como a arma mais utilizada contra vítimas adultas $(52,5 \%)$ e adolescentes $(47,4 \%)$, sendo seguido pelo uso da faca em $32,5 \%$ e 26,3\% nessas mesmas vítimas. Com parâmetros etários da OMS, constatou-se a presença de revólveres em $56,0 \%$ dos crimes cometidos contra adolescentes e em $47,0 \%$ contra adultas, e facas em $38,0 \%$ e $20,0 \%$, respectivamente. Com esse mesmo critério, Peipert \& Domagalski 17 relatam o uso de armas de fogo em 2,0\% dos crimes cometidos contra adultas e em $4,0 \%$ contra as adolescentes, sendo a faca utilizada em $20,0 \%$ e $8,0 \%$ dos crimes envolvendo essas vítimas.

Quando armas não estão presentes na execução do delito, a resistência é a forma de reação mais freqüentemente utilizada pelas vítimas com maior porte físico. Segundo ZouchaJensen \& Coyne 18, o uso dessa estratégia contribuiu para que a ofensa fosse evitada, porém, injúrias adicionais foram observadas em 46,7\% dos casos.

Nos casos em que lesões não-genitais foram constatadas, $75,0 \%$ deles não envolveram o uso de armas, condição que predominou nos dois critérios entre crianças, adolescentes e adultas. Quando utilizadas, verificou-se que as evidências de tais lesões decrescem em número frente ao uso de facas no grupo das adultas e adolescentes $(14,3 \%)$ e de revólveres contra es- 
sas vítimas (10,7\%). Destaca-se a ausência de lesões não-genitais nas vítimas adolescentes e adultas onde objetos foram empregados. Esses dados indicam que o uso de objetos ou armas se relaciona com a ausência de lesões não-genitais, já que a visão das mesmas traz às vítimas o temor do risco de injúrias, fato que propicia a não reação. Contudo, nossa experiência demonstra que muitas vezes, as injúrias físicas são produzidas diretamente pelo uso das armas como instrumentos de agressão, apesar da não resistência das vítimas ou por outras maneiras no decorrer da ofensa.

\section{Considerações finais}

A ausência do uso de violência física e de armas na perpetração de crimes sexuais contra crianças, diferentemente do observado em adolescentes e adultas, reflete certas características que as tornam vítimas ideais. $\mathrm{O}$ ofensor pode aproveitar-se da sua curiosidade natural sobre o sexo, vitimizando principalmente aquelas que não recebem informações sobre sexualidade no meio familiar. Além da impotência física diante das proporções de um adulto, a criança vive num meio de poder detido por pessoas adultas, no qual aprende a obedecê-las e delas depender para sobreviver. Desta forma, a criança é facilmente conduzida por adultos nos quais repousa sua concepção de autoridade. Por outro lado, a necessidade de afeto e atenção pode ser explorada por ofensores sedutores que detêm um grande período de tempo junto às crianças em seus lares, ou por aqueles que deliberadamente passam a fazer parte de suas atividades e recreações, nas lacunas deixadas por pais e familiares ausentes.
Vítimas adolescentes e adultas, por possuírem maior porte físico, são propensas a apresentar reações de resistência. Nesse sentido, o uso de armas, ao provocar nas mesmas o medo extremo de serem mortas, faz com que os ofensores obtenham seus intentos sem a existência de reações.

As evidências de lesões não-genitais em adolescentes maiores de 14 anos e adultas são elementos importantes na verificação do constrangimento e do uso da violência. Contudo, a associação entre estas lesões e a ocorrência do crime é questionável, vez que a ausência de tais injúrias não contradiz as alegações de ofensas a serem tipificadas como crimes sexuais. Mesmo submetida a ato sexual coercitivo, a vítima pode não apresentar evidências físicas, não sendo o fato indicativo de ato sexual consensual. Ainda assim, o achado de lesões nãogenitais se constitui num elemento de peso para as decisões judiciárias.

Nas situações de violência, a interação entre ofensor e ofendido produz danos em graus variáveis que afetam a integridade física e psíquica das vítimas, bem como os horizontes sociais e culturais. Assim, o fenômeno não é apenas uma transgressão de regras e leis, mas também uma relação de poder exercida de forma interpessoal e social. Diante das novas relações de socialização e proteção promovidas pelo Estatuto da Criança e do Adolescente e das penalidades legais impostas aos violadores dos direitos das crianças e adolescentes, torna-se importante a análise do fenômeno por meio desse critério jurídico, no qual o Direito deve ser compreendido como um fato social e não apenas como um conjunto de normas disciplinadoras da vida em sociedade. 


\section{Resumo}

Este estudo tem como objetivo analisar os meios coercitivos utilizados pelos ofensores sexuais e a produção de lesões não-genitais em mulheres crianças, adolescentes e adultas, vítimas de estupro e atentado violento ao pudor notificados pela Delegacia de Defesa da Mulher e examinados no Núcleo de Perícias Médico-Legais de Ribeirão Preto, São Paulo, Brasil, no período de 1996 a 2000. Na distribuição dos casos segundo a idade, utilizou-se o critério estabelecido pelo Estatuto da Criança e do Adolescente. A violência física foi o constrangimento mais empregado contra adultas $(44,1 \%)$ e adolescentes (25,0\%), seguida da grave ameaça em $36,5 \% e$ 17,0\% dos casos, respectivamente. A violência presumida pela innocentia consilii ocorreu em $94,1 \%$ das crianças e 42,8\% das adolescentes. Lesões não-genitais de natureza leve foram evidenciadas em 7,8\% dos casos, acometendo crianças (3,0\%), adolescentes $(7,2 \%)$ e adultas (14,4\%), produzidas sem o uso de armas (75,0\%). Quando utilizadas, constatou-se que o número de casos com lesões decresce frente ao emprego de facas $(14,3 \%)$ e revólveres $(10,7 \%)$ contra vítimas adultas e adolescentes.

Ferimentos e Lesões; Violência;Gênero

\section{Referências}

1. Sediak AJ, Broadhurst DD. Executive summary of the third national incidence study of child abuse and neglect. Washington DC: Administration for Children and Families, U.S. Department of Health and Human Services; 1996.

2. Rennison CM. Criminal victimization 1999. Washington DC: Bureau of Justice Statistics, National Crime Victimization Survey, U.S. Department of Justice; 2000.

3. Faúndes A, Oliveira G, Andalaft Neto J, Lopes JRC. II fórum interprofissional sobre o atendimento ao aborto previsto na lei. Femina 1998; 26:134-8.

4. Organização Pan-Americana da Saúde. Resolução XIX: violência e saúde. Washington DC: Organização Pan-Americana da Saúde; 1993.

5. Minayo MCS, Souza ER. É possível prevenir a violência? Reflexões a partir do campo da saúde pública. Ciênc Saúde Coletiva 1999; 4:7-23.

6. Ministério da Saúde. Prevenção e tratamento dos agravos resultantes da violência sexual contra mulheres e adolescentes. Brasília: Ministério da Saúde; 1999.

7. Código Penal Brasileiro. Lei no 2848 de 7 de dezembro de 1940. São Paulo: Editora Saraiva; 2000.

8. Deslandes SF. O atendimento às vítimas de violência na emergência: prevenção numa hora dessas? Ciênc Saúde Coletiva 1999; 4:81-94.

9. Estatuto da Criança e do Adolescente. Lei no 8069 de 13 de julho de 1990. São Paulo: Fundo Social de Solidariedade; 1990.

10. Bang L. Who consults for rape? Sociodemographic characteristics of rape victims attending a medical rape trauma service at the Emergency Hospital in Oslo. Scand J Prim Health Care 1993; 11:15-20.

\section{Colaboradores}

J. N. Reis contribuiu no levantamento e coleta dos dados e participou da análise dos dados, da revisão desta análise e da elaboração da metodologia, da estrutura do trabalho e das referências bibliográficas. C. C. S. Martin e M. G. C. Ferriani colaboraram na elaboração da metodologia e das referências bibliográficas e participaram da análise dos dados e da revisão desta análise.

11. Widom CS. Victims of childhood sexual abuse later criminal consequences. Washington DC: National Institute of Justice, U.S. Department of Justice; 1995.

12. Prentky RA, Knight RA, Lee AFS. Child sexual molestation: research issues. Washington DC: U.S. Department of Justice; 1997.

13. Ferreira JD. Estudo de fatores relacionados com a violência sexual contra crianças, adolescentes e mulheres adultas [Tese de Doutorado]. São Paulo: Centro de Referência da Saúde da Mulher e de Nutrição, Alimentação e Desenvolvimento Infantil; 2000.

14. Pease T, Frantz B. Your safety...your rights. Personal safety and abuse prevention education program to empower adults with disabilities and train service providers. Doyleston: Network of Victim Assistance; 1994.

15. Cohen C, Matsuda NE. Crimes sexuais e sexologia forense: estudo analítico. Revista Paulista de Medicina 1991; 109:157-64.

16. Pimentel S, Schritzmeyer ALP, Pandjiarjian V. Estupro: crime ou "cortesia"? Abordagem sociojurídica do gênero. Porto Alegre: Editora SAFE; 1998.

17. Peipert JF, Domagalski LR. Epidemiology of adolescent sexual assault. Obstet Gynecol 1994; 84: 867-71.

18. Zoucha-Jensen JM, Coyne A. The effects of resistance strategies on rape. Am J Public Health 1993; 83:1633-4.

Recebido em 29/Out/2002

Versão final reapresentada em $07 / \mathrm{Jul} / 2003$

Aprovado em 23/Out/2003 